\title{
Defaulters of Tuberculosis Treatment Among MDR-TB Patients Attended in Forlanini/Lazaretto Hospital, Mogadishu, Somalia
}

\author{
Ahmed Hussein 1, *, Omar Dahir ${ }^{2, ~ *, ~ A b d i r i s a k ~ Y u s u f ~ A h m e d ~}{ }^{3}$, Gallad Dahir Hassan ${ }^{4}$, \\ Samio Mohamud ${ }^{5}$ \\ ${ }^{1}$ Department of Public Health, College of Medicine and Health Science, Mogadishu University, Mogadishu, Somalia \\ ${ }^{2}$ College of Medicine and Health Science, Zamzam University of Science and Technology, Mogadishu, Somalia \\ ${ }^{3}$ Martino Hospital, Mogadishu, Somalia \\ ${ }^{4}$ Department of Public Health, College of Medicine and Health Science, Jamhuriya University of Science and Technology, Mogadishu, \\ Somalia \\ ${ }^{5}$ Somali Public Health Association, Mogadishu, Somalia
}

Email address:

ahmed@sopha.so (A. Hussein), omarshaani@gmail.com (O. Dahir),drjalaal@hotmail.com (A. Y. Ahmed), galladph@gmail.com (G. D. Hassan), samiosom65@gmail.com (S. Mohamud)

${ }^{*}$ Corresponding author

\section{To cite this article:}

Ahmed Hussein, Omar Dahir, Abdirisak Yusuf Ahmed, Gallad Dahir Hassan, Samio Mohamud. Defaulters of Tuberculosis Treatment Among MDR-TB Patients Attended in Forlanini/Lazaretto Hospital, Mogadishu, Somalia. Central African Journal of Public Health. Vol. 7, No. 3, 2021, pp. 144-148. doi: 10.11648/j.cajph.20210703.18

Received: March 24, 2021; Accepted: April 8, 2021; Published: June 21, 2021

\begin{abstract}
Background: Tuberculosis (TB) is a global public health issue, it's one of the oldest diseases known to affect humans which remains one of the highest leading of mortality worldwide. The main purpose of this study was to assess the factors which influencing to non-adherence TB- Treatment (Defaulters) among TB patient at Forlanini/Lazaretto Hospital-Mogadishu-Somalia. Methodology: - descriptive cross-sectional hospital-based study was conducted among patients who were not-adhered their medication attending TBMUs (FORLANINI/LAZARETITO Hospital-Mogadishu-Somalia)-from March to May 2019. A total of 103 defaulters were the respondents during the study period by using non-probability convenient sampling method. Data were collected by using structured questionnaire. Descriptive statistics was used using SPSS version 20 statistical software. The data were showed tables, figures and graphs for describing the data. Results: This study shades light on the defaulters of tuberculosis treatment among TB patients and it shows that the male population are the most people among the population who fail to complete the TB course of medication treatment with a percentage of $79.6 \%$ and women are recorded having much less percentage of defaulting TB medication with a percentage of $20.4 \%$. In terms of education, those who have never been to school and the secondary level are least likely to default the medication with a percentage $12.6 \%$ each, followed post graduate level with $16.5 \%$ and university level having a percentage of $19.4 \%$. The most likely patients that can default TB medication are the primary level population with a percentage of $38.8 \%$ the unemployed and the employed population have slight difference in the percentage of people who defaults the medication of TB with $32.0 \%$ and $30.1 \%$ respectively. The mothers who are housewives have a percentage of $16.5 \%$ and finally the employers have a percentage of $21.4 \%$ TB medical treatment defaults. Conclusion: the study concluded and recommended that there are urgent needs for continuous and effective health education for the patients and their families and social support when starting the medications to ensure adherence and compliance to anti tuberculosis drug as well as regular monitoring, counseling and follow-up with the patients and access to drugs and health care centers.
\end{abstract}

Keywords: Tuberculosis, Adherence, Tuberculosis Treatment, Non-adherence, Defaulters 


\section{Background}

Tuberculosis (TB) remains a major public health problem worldwide. There were 8.6 million new TB cases and 1.3 million TB deaths in 2012. The African region alone accounted for $27 \%$ of the world's cases and the highest rates of cases and deaths relative to population (225 incident cases per 100,000 on average and more than double the global average of 122 [1]. It remains a major cause of morbidity and mortality in many developing countries. Approximately $95 \%$ of all TB cases and $99 \%$ of deaths occur in developing countries, with the greatest burden in sub-Saharan Africa and South East Asia. In addition, TB hinders socioeconomic development, because $75 \%$ of people with TB are within the economically productive age group of $15-54$ years [2]. TB is a major health burden in Somalia, contributing significantly to the reported high morbidity and mortality among the population. The epidemiology of TB in Somalia is similar to that found in many other developing countries where the disease is closely associated with widespread poverty, poor living conditions and reduced immune state especially those living with HIV and AIDS. According to WHO, TB in Somalia is the leading cause of morbidity and mortality among the adult population, contributing to significant loss in work productivity and increased household expenses in support of affected member of the household during the long treatment of TB. The Global Fund TB program in Somalia was found to have significantly contributed to the general betterment of the health status of the population by reducing the impact of TB on the population. The national program to manage and control the spread of TB in Somalia is supported by the large grant from the Global Fund, administered through the World Vision International (Somalia) as the Principal Recipient of the Global Fund and implemented through a total of sub recipients implementing different components of the program in the different regions of Somalia [3]. Although current policies and strategies for global TB control promote a patient-centered approach (PCA), actually putting this approach into practice can be challenging. Applying a PCA requires a new way of thinking, teaching, communicating, and delivering services. TB control programs and their partners need easy-to-use tools that can help adapt the concept of patient-centered care to their own local context [4]. Treatment adherence is one of key Aspects for disease control since treatment failure may result in long term infectiousness and higher rates of unsuccessful therapy and this may lead to high transmission, drug resistance, and death. [5]. The World Health Organization (WHO) recommends that non-adherence should be at least 5\% [6]. In 1993, the world health organization stated emergency of global tuberculosis because of increasing high burden of TB worldwide. In 1995, the DOTS (Direct Observed Treatment Short Course) strategy has been established in order to achieve TB control worldwide so that the main target of this strategy was to achieve $70 \%$ case-detection and $85 \%$ treatment rate by 2005 . Therefore, DOTS ensures adherence to TB treatment. DOTS is watching the patient swallow the medication for all doses over the treatment regimen by a supervisor [7]. In 2003, DOTS accomplished to cure about 84 of all detected patients, unfortunately detected only $28 \%$ of TB cases globally. However, this target $70 \%$ of case detection has not been achieved until 2013 [8]. DOTS have five key components: government commitment to sustained TB control activities; case detection by sputum smears microscopy among symptomatic patients self-reporting to health services; standardized treatment regimen of six to eight months for at least all confirmed sputum smears positive cases; a regular, uninterrupted supply of all essential anti-TB drugs; a standardized recording and reporting system that allows assessment of treatment results for each patient and of the TB control programme overall. [9]. Sustainable development goal (SDG3) is to "Ensure healthy lives and promote well-being for all at all ages", One of these targets, Target 3.3, explicitly mentions TB: "By 2030, end the epidemics of AIDS, tuberculosis, malaria and neglected tropical diseases, and combat hepatitis, waterborne diseases and other communicable diseases [10]. Tuberculosis became worldwide public health problems, despite the fact that the causative organism was discovered before 100 years and highly effective drugs and vaccine are available making tuberculosis a preventable and curable disease. Technologically advanced countries have achieved accomplishment results in the control of tuberculosis, this decline started long before the advent of BCG or a chemotherapy and has been related to changes through improvements in the standards of living and quality of life of the people coupled with the application of available technical knowledge and health resources [11].

\section{Methods and Materials}

\subsection{Study Setting}

Descriptive cross-sectional hospital-based study conducted to assess factors related to non-adherence of TB treatment among MDR-patients attending lazaretto hospitalMogadishu-Somalia. Face-to-face interview questionnaire was performed during the study.

\subsection{Study Site}

This research was undertaken in Forlanini/lazaretto Hospital, located in Benadir region Mogadishu, Somalia, (Lazaretti Hospital), and located in Abdi Aziz district north Mogadishu it was one of the largest and is the only mental hospital and Recently Became MDR-TB in Mogadishu and plays an extremely important role for the community in this City of conflict.

\subsection{Study Population}

The study population in this study was patients with multidrug-resistant tuberculosis in Forlanini/lazaretto Hospital who interrupted the medication and greed to participate by signing an informed consent was included into the study. Patients who were seriously sick and unable to interview 
during the study period and patients who felt uncomfortable to answer the questions and refused to participate were excluded.

\subsection{Sampling and Sample Size}

The study was selected using a convenience nonprobability sampling method was used. Sampling out of a 103 defaulter patients who entering the hospital at time of filling the questionnaire from February to May 2019 and interrupted their medication.

\subsection{Ethical Considerations}

The researchers was explained the purpose and benefits of the study to the subjects and ask them for their permission to answer the questions. Participation in the study was totally voluntary. Participants were not forced to participate in the study. Even those who initially accepted to participate were free to withdraw in the course of the study if they did not wish to continue Ethics approval was obtained from Mogadishu University and a written informed consent was obtained from all respondents before interviewing. The Statistical package for the social science (SPSS), version 24, was used for the data analysis.

\section{Results}

\subsection{Demographic Characteristics}

This result shades light on the defaulters of tuberculosis treatment among TB patients and it shows that the male population are the most people among the population who fail to complete the TB course of medication treatment with a percentage of $79.6 \%$ and women are recorded having much less percentage of defaulting TB medication with a percentage of $20.4 \%$. In terms of education, those who have never been to school and the secondary level are least likely to default the medication with a percentage $12.6 \%$ each, followed post graduate level with $16.5 \%$ and university level having a percentage of $19.4 \%$. The most likely patients that can default TB medication are the primary level population with a percentage of $38.8 \%$ the unemployed and the employed population have slight difference in the percentage of people who defaults the medication of TB with $32.0 \%$ and $30.1 \%$ respectively. The mothers who are housewives have a percentage of $16.5 \%$ and finally the employers have a percentage of $21.4 \%$ TB medical treatment defaults. The low income population have the highest percentage of $68.9 \%$ followed by the medium income group with $30.1 \%$ and finally the least among them are those who have high income with a percentage of only $1.0 \%$. In terms of marital status, the divorced have the least percentage of defaulting TB medication of $1.9 \%$. The married and those who have not married yet have the percentage of $55.3 \%$ and $42.9 \%$ respectively. The number of rooms in the house also affects the defaulters of TB medication as shown in this study. the house with three rooms and more have a percentage of $46.6 \%$ and the house with two rooms have a percentage of $35.0 \%$ and the single room house has a percentage of $18.4 \%$ and the number of people per room have a connection with defaulters as the people who are more than four in a room have a percentage of $14.6 \%$.

Table 1. Demographic and characteristics of the study population.

\begin{tabular}{|c|c|}
\hline Variables & $\mathbf{N} \%$ \\
\hline \multicolumn{2}{|l|}{ Sex } \\
\hline Male & $79.6 \%$ \\
\hline Female & $20.4 \%$ \\
\hline \multicolumn{2}{|l|}{ Educational Level } \\
\hline Illiterate & $12.6 \%$ \\
\hline Primary & $38.8 \%$ \\
\hline secondary school & $12.6 \%$ \\
\hline university level & $19.4 \%$ \\
\hline post graduate/ above university & $16.5 \%$ \\
\hline \multicolumn{2}{|l|}{ Occupation } \\
\hline Housewife & $16.5 \%$ \\
\hline Employee & 30.1 \\
\hline Employer & $21.4 \%$ \\
\hline Not employed & $32 \%$ \\
\hline \multicolumn{2}{|l|}{ Income } \\
\hline Law & $68 \%$ \\
\hline Medium & $30.1 \%$ \\
\hline High & $1 \%$ \\
\hline \multicolumn{2}{|l|}{ Marital Status } \\
\hline Married & $55.3 \%$ \\
\hline Not Married & $42.9 \%$ \\
\hline Divorced & $1.9 \%$ \\
\hline \multicolumn{2}{|l|}{ Number of Rooms in the house } \\
\hline One & $18.4 \%$ \\
\hline Two & $35 \%$ \\
\hline Three & $46.6 \%$ \\
\hline \multicolumn{2}{|l|}{ Number of people per room } \\
\hline One & $5.8 \%$ \\
\hline Two & $38.8 \%$ \\
\hline Three & $32 \%$ \\
\hline Four & $8.7 \%$ \\
\hline More than four & $14.6 \%$ \\
\hline \multicolumn{2}{|l|}{ Place of residence } \\
\hline Urban & $56.3 \%$ \\
\hline Rural & $43.7 \%$ \\
\hline
\end{tabular}

The percentage of two and three people in a room are slightly identical with $38.8 \%$ and $32.0 \%$ respectively. Four people in a room have a percentage of $8.7 \%$ and a single person have the least percentage of $5.8 \%$. The urban population are more likely to default TB medication with a percentage of $56.3 \%$ compared to those who are in rural areas reflecting a percentage of $43.7 \%$.

\subsection{Knowledge of the Patients Towards the Mode of the TB Spread and the Importance of TB Treatment}

The majority of the population have knowledge about that TB treatment is important with a percentage of $95.1 \%$ and very few people, $4.9 \%$ only are not aware of the importance of treating the disease. From that knowledge significant number, $93.2 \%$ of the population also have the knowledge about that TB can be treated and only $6.8 \%$ don't have a clue on whether TB is treatable or not. Many people have the knowledge about the consequence of interruption of $\mathrm{TB}$ treatment with $83.5 \%$ saying that defaulting TB treatment have consequences and only $16.5 \%$ are not aware of the 
consequence of not completing the medication or interrupting it. The types of TB treatment is not that much familiar within the population as it indicated in this report in which $38.8 \%$ say they don't know the types of TB treatment and $61.2 \%$ have the knowledge about the types of treatment. The side effect of TB treatment awareness is almost identical as it is shown in this report. $54.4 \%$ said they have the knowledge of the side effects of TB treatment and $45.6 \%$ don't have the knowledge of the side effects of the medication of TB. Interruption of TB medication will definitely mean one have to start again, from the study, a large quantity of the population $75.7 \%$ have that knowledge and $24.3 \%$ don't know if they will restart the medication once they defaulted. Figure 1 illustrated emotional part as a factor of associated with non-adherence of treatment, and it revealed that (85.4\%) of the respondents were felt better while $(14.6 \%)$ were not, $(52.4 \%)$ were thought that the drug was important while $(47.6 \%)$ were didn't think that the drug was important, $(51.5 \%)$ were depressed while $(48.5 \%)$ were did not, $(65 \%)$ were do believe that they have TB while $(35 \%)$ were didn't believe they have TB, (55.3\%) were not addicting alcohol too much while $(44.7 \%)$ were addicting alcohol too much and $(65 \%)$ were got tired swallowing the drug daily while (35\%) were did not swallowing the drug daily.

Table 2. Knowledge of the patients towards the mode of the TB spread and the importance of TB treatment.

\begin{tabular}{ll}
\hline Variables & $\mathbf{N \%}$ \\
\hline Knowledge about that TB treatment is important & \\
Yes & $95.1 \%$ \\
No & $4.9 \%$ \\
Knowledge about that TB can be treatable & \\
Yes & $93.2 \%$ \\
No & $6.8 \%$ \\
Knowledge about the consequences of interruption of treatment & \\
Yes & $83.5 \%$ \\
No & $16.5 \%$ \\
Knowledge about types of TB treatment & $21.4 \%$ \\
Yes & $61.2 \%$ \\
No & $38.8 \%$ \\
Knowledge about the side effect of TB treatment & $68 \%$ \\
Yes & $54.4 \%$ \\
No & $45.6 \%$ \\
Knowledge about the drugs interrupted will restart & \\
Yes & $75.7 \%$ \\
No & $24.3 \%$ \\
Divorced & $1.9 \%$ \\
Knowledge about DOTS (direct observed treatment) & \\
Yes & $57.3 \%$ \\
No & $42.7 \%$ \\
\hline
\end{tabular}

\section{Discussion}

Tuberculosis is one of the deadliest disease in the world if not treated well. It estimated that about 9 million people around the world developed tuberculosis and nearly 2 million people died with or from the disease [12]. Drug resistance, and eventually multidrug resistance is expected to occur whenever patients fail a course of anti TB treatment [13]. Treatment of resistance is more costly and more complex if second line drug are used and failure and deaths are more frequent. Tuberculosis drug defaulters are more likely to happen to men in Somalia compared to the men in Uganda [14], this is because the men in Somalia don't take the disease very serious and after they feel better they will avoid taking the drugs due to the long duration of the medication also illiteracy plays an important role in defaulting the medication of tuberculosis as this is indicated in a study that was carried out in Kenya [8,9] which shows the Somali population have less education compared to in the people in Kenya [15]. Many women are more likely to have been employed in Sudan than in Somalia and this will have a direct impact on finishing medications such as Tuberculosis disease as it requires dedications and time and as a result the women in Somalia are likely to default the drugs of tuberculosis. The unemployed members of the population in Somalia is very high compared to those in Kenya and this will increase the level of poverty in the population due to the reduced income per month and this will reduce the use of TB medication in Somalia than in Kenya increasing the defaulters of the TB treatment. The number of rooms in the house and the number of people per room also have a significant impact on the reduced usage or the stoppage of the TB treatment medication as a previous study carried out in turkey shows that people living in houses with many rooms have higher chances of completing their treatment of diseases than those who live in a single room in Somalia with more than two people. Urbanization also has an impact on treatment of tuberculosis. The cities or the urban places have higher chances of getting readily available and affordable medications than in rural areas. Cities in Somalia are very few compared to other African countries such as Tanzania or Uganda and this means that in Somalia people are most likely to live in rural areas and it will be difficult for them to get a complete tuberculosis treatment leading to the defaulting after sometime.

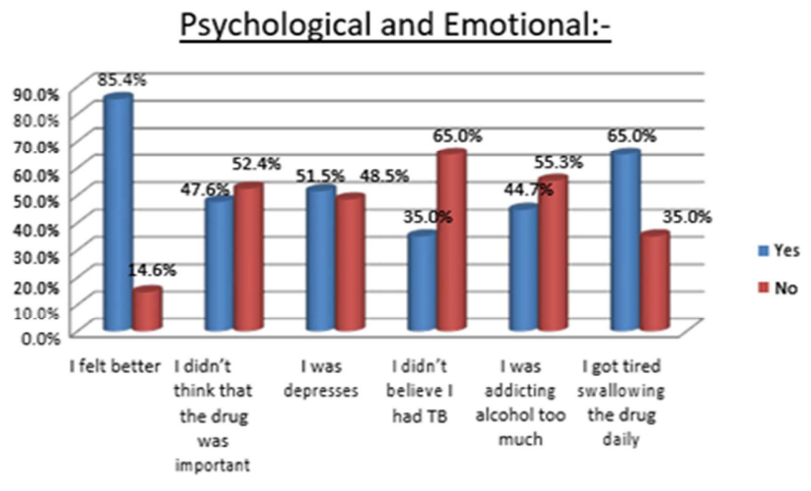

Figure 1. Main risk factors associated with non-adherence of treatment.

Knowledge about type of TB treatment and the importance of treating oneself after infection also have a different perspective among the people in Somalia and the communities in other countries such as Kenya as it was shown in previous studies that was carried in Kenya which indicated that people are more likely to finish the medications of tuberculosis when they know the 
consequences of interruption of treatment than when they don't know like the cases in Somalia in which people are more likely to stop the treatment before its required time due to lack of knowledge of interruption of treatment which will lead to restart.

\section{Conclusion}

The study concluded and recommended that there are urgent needs for continuous and effective health education for the patients and their families and social support when starting the medications to ensure adherence and compliance to anti tuberculosis drug as well as regular monitoring, counseling and follow-up with the patients and access to drugs and health care centers.

\section{Data Availability}

The data used to support the findings of this study are available from the corresponding author upon reasonable request.

\section{Ethical Consideration}

Ethics approval was obtained from the Mogadishu University, college of Medicine and Health science. A formal permission letter was taken from the hospital management before the beginning data collection.

\section{Conflict of Interest Statement}

The authors declare that they have no competing interests.

\section{Acknowledgements}

We want to express our heartfelt thanks to Mogadishu University, College of Health and Medical Sciences. We also extend our thanks to hospital administrative for allowing us to collect data from patients, Authors would also greatly appreciate the study participants provided us with all necessary information.

\section{References}

[1] Lilian Bulage et al, The Quality of Tuberculosis Services in Health Care Centres in a Rural District in Uganda: The Providers' and Clients' Perspective, Hindawi Publishing Corporation Tuberculosis Research and Treatment Volume 2014, Article ID 685982, 11 pages.

[2] Belay Mergya Eticha et al, Patients' perspectives of the quality of tuberculosis treatment services in South Ethiopia, American
Journal of Nursing Science. Vol. 3, No. 4, 2014, pp. 48-55. doi: 10.11648/j.ajns.20140304.12.

[3] World vision, an impact evaluation of the world vision managed TB program, report on the evaluation of the global fund TB program in Somalia (2013).

[4] Dye C, Gamett GP, Sleeman K, Williams BG: Prospects for worldwide tuberculosis control under the WHO DOTS strategy. Lancet 1998, 352: 1886-91.

[5] World Health Organization: Treatment of Tuberculosis Guidelines for National Program. WHO/CDS/TB/2003.313. Third edition. Geneva, Switzerland: World Health Organization; 2003.

[6] Pablos-Méndez A, Knirsch CA, Barr RG, Lerner BH, Frieden TR: Non- adherence in tuberculosis treatment: predictors and consequences in New.

[7] World Health Organization WHO, Report on Treating patients for multidrug-resistant tuberculosis in Somalia; 2014 access available: $\quad \mathrm{http} / / \mathrm{www} . e m r o . w h o . i n t / s o m / s o m a l i a-$ news/multidrug-resistant tuberculosis-somalia-treatment.html.

[8] Talbot E A, Halabi S, Manchanda R, Mwansa M A, Wells C D. Knowledge, attitude, and beliefs about directly-administered antiretroviral therapy among tuberculosis patients, Botswana 2002. Int J STD AIDS 2004; 15: 282-283.

[9] Finlay A F, van der Walt M, Holtz T H, Thorpe, L E, Wells C $\mathrm{D}$, Weyer K. Treatment outcomes of patients with multidrug resistant tuberculosis in South Africa using a standardized regimen, 1999-2000. Boston, MA: Infectious Disease Society of America, September 2004, Poster session 58, N_2101.

[10] World Health Organization. Adherence to long term therapies: evidence for action. WHO/MNC/03.01. Geneva, Switzerland: WHO, 2003.

[11] Sumartojo E. When tuberculosis treatment fails: a social behavioural account of patient adherence. Am Rev Respir Dis 1993; 147: 1311-1320.

[12] Prassad R, Rizavi DM, Surya Kant and A Jain. A comparison of unsupervised treatment along with intensive health education and directly observed treatment in pulmonary tuberculosis. Indian Journal of Tuberculosis. 2001; 48 (1): 21-24.

[13] Bhat S, Singal N, Aggarwal CS and Jain RC. Knowledge attitudes and practices of newly diagnosed sputum positive cases of pulmonary tuberculosis. Journal of Communicable Diseases. 1999; 31 (4): 247-252.

[14] Sawsan Elbireer, David Guwatudde, Peter Mudiope, Juliet Nabbuye-Sekandi and Yukari C. Tuberculosis treatment default among HIV-TB co-infected patients in urban Uganda. Journal of Tropical Medicine and International Health. doi: 10.1111/j.1365-3156.2011.02800.

[15] Bernard N Muture, Margaret N Keraka, Peter K Kimuu, Ephantus W Kabiru, Victor O Ombeka and Francis Oguya. Factors associated with default from treatment among tuberculosis patients in nairobi province, Kenya: A case control study. doi: 10.1186/1471-2458-11-696. 